\title{
大迎角を持つ軸対称放物体背後に生じる剥離渦の非定常特性の解明*1 Clarification of Unsteady Characteristics in Separated Flow over Axisymmetric Paraboloid at High Angles of Attack
}

\author{
石 出 忠 輝*2 西 川進 栄*3 \\ Tadateru Ishide, Nobuhide NishiKawa and Fumihiko Mikami
}

Key Words: Three Dimensional Separated Flow, Velocity Fluctuation, Hot Wire Anemometer, Probability Density Function

\begin{abstract}
The phenomenon of three-dimensional separation of the flow over a slender body at high angles of attack is difficult to model and still challenging problem. The singularity of the flow is caused by mutual intervention of threedimensional separation and separated vortices. In this study, the flow in the cross-flow separation region of an axisymmetric paraboloid at 30,40, and $50 \mathrm{deg}$ angle of attack has been investigated experimentally by hot wire anemometer. Reynolds numbers are $9.0 \times 10^{3}$ and $1.8 \times 10^{4}$ referred to the base diameter. X-type probe was used to measure three dimensional velocity fluctuations over the axisymmetric paraboloid at sampling time of $4 \mathrm{kHz}$. It has been shown that the lift-off and mergence of vortices can be explained by r. m. s. distribution of velocity fluctuations. Reynolds stress and the difference between probability density function and normal distribution oscillates where the kink of vortex is observed.
\end{abstract}

\section{1.はじめに}

大きな迎え角をとる有限長さの細長物体まわりの流れ は，主として航空・宇宙の分野において多くの実用例があ り、実験及び数值解析の両面から研究が進められている。 特に宇宙飛行体の回収・着陸には高速のみならず，低速時 のデータが必要とされるが, 低速時の特性は高速時と比較 して複雑であり, 迎角, レイノルズ数, 頂角など多くのパ ラメータによって変化する. また大迎角物体背後の流れの 剥離と後流のパターンは非常に複雑な様相を呈し1), それ らが空気力の非線形性と特異性を引き起こしていることは 容易に予想できる。したがって，その流れの特性を定性 的, 定量的に把握することは実用的にも非常に重要であ る.このような観点から軸対称物体を対象として，境界層 内の流れの状態が剝離領域に及ほす影響7,11)や三次元剥離 位置の幾何学的な定義及びレイノルズ応力, 表面摩擦応力 の測定による定量的な定義が様々な迎角，レイノルズ数に おいて提案されている4 6,8).さらに大迎角になると剥離渦 が非対称になり、物体に作用する横力発生に重要な影響を 持つと考えられ多くの研究が行われている2,3,9,10). また最 近の可視化技術の進歩にともない, 断面剝離渦の詳細な構 造も解明されてきている1,10)。著者らも従来から軸対称放 物体を対象として，I型プローブを用いた熱線流速計によ る境界層厚さの測定ならびにパワースペクトルの算出，ト レーサ法とレーザライトシート光を組合わせた流れの可視

\footnotetext{
*1平成 12 年3月 23 日、日本航空宇宙学会第 31 期年会謴演会にて 講演。平成 12 年 4 月 4 日原稿受理

*2 木更津工業高等専門学校機械工学科

${ }^{* 3}$ 千葉大学工学部電子機械工学科
}

化と画像解析を通して，軸対称放物体全体にっける剥離線 と剶離渦の位置変化及びパワースペクトルの最大值に着目 した剥離線の定量的な識別等を行ってきた ${ }^{12,13)}$. また著者

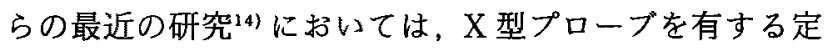
温度型熱線流速計を用いて軸対称放物体背後に生じる剥離 渦内の三次元速度場を測定し，物体壁面近傍に扔いて二次 渦の存在する領域で速度変動の r. m.s. 值が最大になるこ とが示された。しかしながら後流剥離渦全体にわたる非定 常特性，特に久保田らによって指摘されている剥離渦の合 体、浮き上がり、折れ曲がり現象 ${ }^{11}$ が剥離渦内の流れに及 ぼす乱れの影響については未だ明らかにされているとは言 い難い. 本研究ではX型プローブを有する熱線流速計を 使用して, 軸対称放物体背後の剝離領域の速度場を詳細に 測定し，各断面における r.m.s. 分布及びレイノルズ応力 分布の算出に加えて, 確率密度関数を用いて剥離渦の分類 を行い, 剥離渦の合体, 浮き上がり, 折れ曲がり現象を定 量的に明らかにすることを目的としている。

\section{2. 実 験 装 置}

本研究において使用した風洞はゲッチンゲン型であり， 風洞測定部は開放型，测定部長さ $650 \mathrm{~mm}$ である。また 測定部断面積は上流側で $400 \times 400 \mathrm{~mm}$ ，下流側では $550 \times 550 \mathrm{~mm}$ であり，模型の位置する断面において一様 流が得られる有効範囲は $450 \times 450 \mathrm{~mm}$ になっている。こ

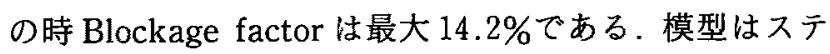
ンレス製で, 全長 $140 \mathrm{~mm}$, 後端直径 $75 \mathrm{~mm}$ の回転放物 体であり，模型先端から中心軸方向距離を $x$ とすると， 任意の $x$ に扔ける模型断面半径 $r$ は $r=\sqrt{10 x}$ で表され る.さらに模型支持のため全長 $350 \mathrm{~mm}$ の鉄製円筒が模 


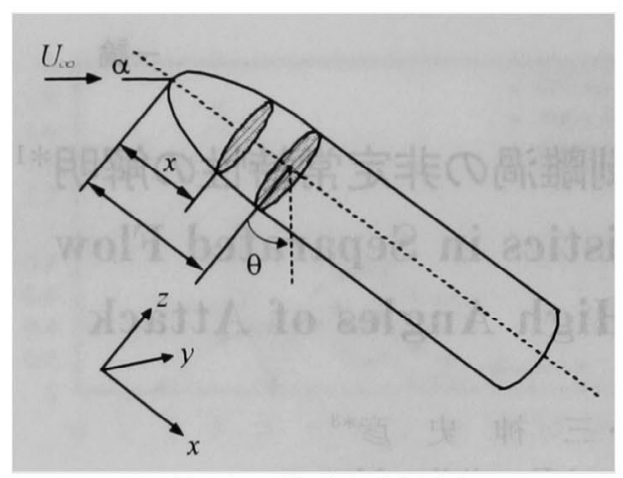

第 1 図 模型及び座標系

型後部に接続されている，第1図に座標系を示す.

\section{3. 実験方法と計測システム}

本研究では，放物体背後の剥離領域における非定常特性 を定量的に求めるために熱線流速計を用いて測定を行う。 使用した熱線流速計は KANOMAX IHW-100であり，定 温度流速計モジュール 2 個と温度補正用温度測定モジュー ルで構成されている，測定简所は周方向については， $\theta=$ $90 \sim 180^{\circ}$ を $11.25^{\circ}$ おきに 8 分割し，さらに著者らが行っ てきた可視化実験 ${ }^{13)}$ から判定される二次渦近傍において 2 点追加設定している.また $\theta=90^{\circ} の y$ 方向主流領域側に $3 \mathrm{~mm}$ 間隔で 3 点設定している. $x$ 方向については $x / L=$ $0.21 \sim 1.0$ において可視化画像から特長的な断面剝離渦パ ターンの観察される箇所を測定点としている。また $z$ 方 向は物体表面直上 $0.5 \mathrm{~mm}$ を開始点として, 主流領域に 至るまでの間を 20 分割している。したがって放物体全体 にわたる測定点数は 280 となる，また物体全体にわたる測 定として物体表面から $1 \mathrm{~mm}$ シフトした点のみを $\theta=$ $90 \sim 180^{\circ}, x / L=0.21 \sim 1.0$ において测定を行った。この 場合の測定点数は 132 点となる. プローブはX型を使用 し，各測定点において平均速度べクル及び変動強さの算 出を行う. 測定手順としてはプローブを 2 個使用し，それ ぞれ配置を変えて測定する.すなわち，一つはプロープ先 端のタングステンワイヤを $x y$ 平面内に設置し $x$ 及び $y$ 方向速度成分 $u, v$ の測定を行い（UV 配置と呼ぶ），も う一方は UVプローブに対して $90^{\circ}$ 回転させ， $x z$ 平面内 にタングステンワイヤを設置し $x$ 及び $z$ 方向速度成分 $u$ ， $w$ の測定を行っている（UW 配置と呼ぶ）。このようにし て $x, y, z$ 三方向の速度成分を捉えている．プロープの 校正方法は，模型をはずした状態で熱線プローブとピトー 管を風洞測定部にセットし，一様流速を 0 10 (m/sec)

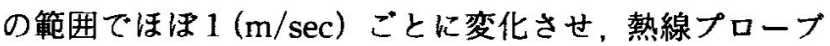
出力とピトー管加ら得られる流速から 4 次式の校正曲線を 得ている。な挍正時のプローブの位置決めは，それぞれ のプローブにおいて 以外の速度成分が 0 になるように 行っている、本実験におけるサンプリング周波数は 4 $\mathrm{kHz}$, サンプリングデータ数は 16,384 である。姦理帯域 については事前に予備実験として，熱線プローブを軸対称 放物体まわりに順次動かし，出力信号を信号解析ソフト Spectra Pro (Sound Technology 社) を用いて FFT 解析

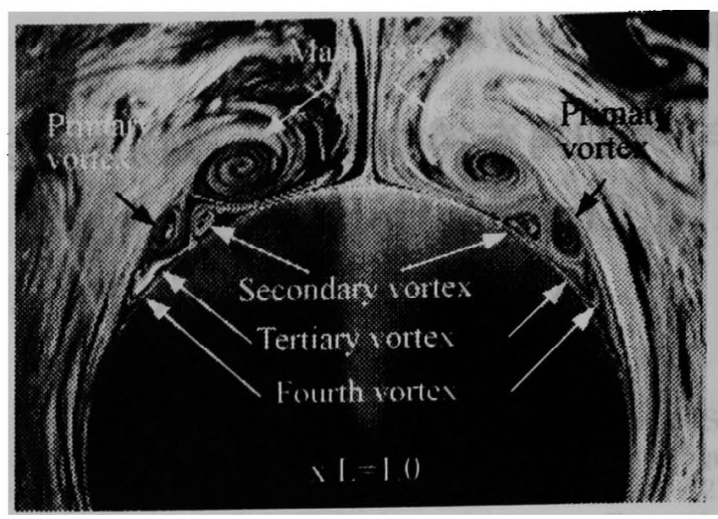

第 2 図 可視化画像 $\left(\alpha=40^{\circ}, R e=9.0 \times 10^{3}, x / L=1.0\right)$

することによって決定している．

\section{4. 結果と考察}

本実験で使用した風洞の残留乱れは一様流速 $U_{\infty}=1.8$ $(\mathrm{m} / \mathrm{sec})$ の場合 $0.7 \%, U_{\infty}=3.6(\mathrm{~m} / \mathrm{sec})$ の場合 $1.1 \%$ である.また一様性は $U_{\infty}=1.8(\mathrm{~m} / \mathrm{sec})$ の場合 $0.8 \%$ ， $U_{\infty}=3.6(\mathrm{~m} / \mathrm{sec})$ の場合 $2.6 \%$ であり，本計測結果に大 きな影響を与えるには至らないと考えられる．模型の閉塞 効果による影響は，閉塞効果を最大限に見積もるために風 洞測定部が密閉型であると仮定し連続の式を適用すると， 軸対称放物体まわりの流速は $\alpha=30^{\circ}$ の場合では模型のな い状態における風洞測定部一様流速の 1.10 倍, $\alpha=40^{\circ}$ で は 1.13 倍， $\alpha=50^{\circ}$ では 1.16 倍程度である.しかしなが ら本実験における風洞測定部は開放型であり，閏塞効果は 密閉型と比較して小さくなるものと考えられるため, 本研 究においては閉塞効果修正を行っていない．また円筒部分 から放出される渦が，放物先端模型まわりの流れに与える 影響については，軸対称放物体の先端から前方 $50 \mathrm{~mm} の$ 断面における流れの一様性及び残留乱れが模型のない状態 における風洞測定部一様流速の值と同程度であることか ら，小さいものであると考えられる. 第 2 図に $\alpha=40^{\circ}$ ， $R e=9.0 \times 10^{3}, x / L=1.0$ における可視化画像を示す．こ

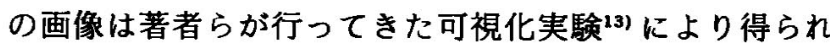
たものである．この図より背中側対称線から周方向上流側 に向けて，主渦，一次渦，二次渦，三次渦が形成されてい ることが分かる．隣接した渦の回転方向は逆転しており， 一次剝離線から剝離した流れと背中側対称線からの再付着 流れによって主渦が形成された後，各綐渦が相互干涉的に 生成されるものと考えられる。

4.1 速度变動の r.m.s. 分布 第 3 図に $\alpha=40^{\circ}, R e$ $=9.0 \times 10^{3}$ における $y$ 方向速度成分 $v$ の r.m.s. 分布を示 す．なおこの図におけるr.m.s. 值は一様流速 $U_{\infty}$ て無次 元化している． $x$ 方向速度成分 $u, z$ 方向速度成分 $w$ に ついても同粎の傾向を示している．この図から各断面共に 第 2 図における二次渦領域において最大値を示しているこ とが確認できる，また一次渦から主渦の渦核に至る領域 は，二次渦領域に次いで高い値を示している．等値線が密 になっている部分に着目すると，物体後方における剥離渦 


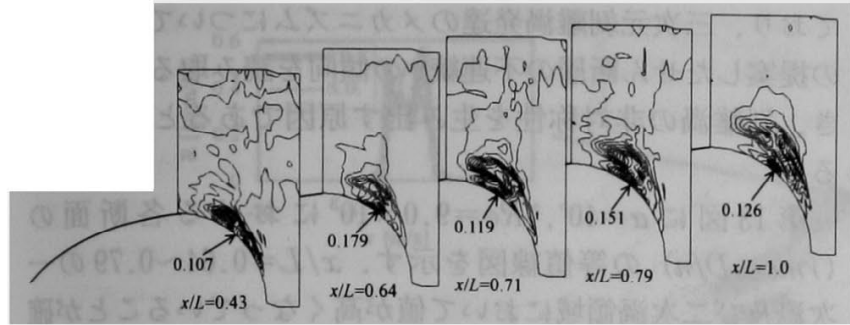

第 3 図 各断面に招ける r.m.s. 分布 $\left(\alpha=40^{\circ}, R e=9.0 \times 10^{3}\right)$

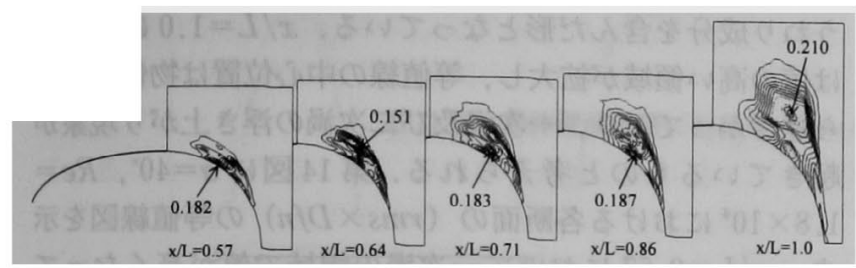

第 4 図 各断面における r. m. s. 分布 $\left(\alpha=40^{\circ}, R e=1.8 \times 10^{4}\right)$

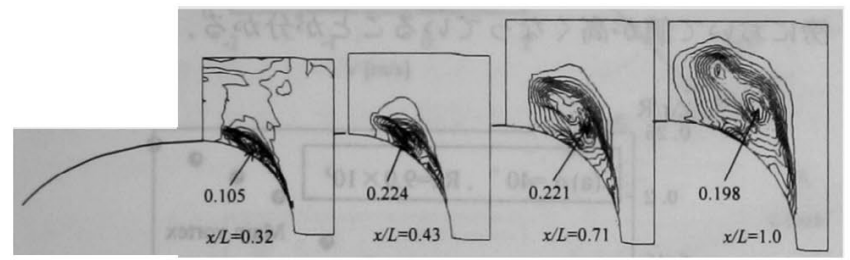

第 5 図各断面における r.m.s. 分布 $\left(\alpha=50^{\circ} ， R e=1.8 \times 10^{4}\right)$

領域の拡大が観察できる.第 4 図に $\alpha=40^{\circ}, R e=1.8 \times$ $10^{4}$ におけるr.m.s. 分布を示す. $x / L=0.64$ において r.m.s. 值の最大値が主渦領域側に移動しており，二次渦 領域で発生した乱れが主渦領域側に拡大していることが分 かる.また $x / L=0.86$ において r.m.s. 值の最大值は、物 体壁面から離れて存在しており，二次渦の浮き上がりが確 認できる.さらに $x / L=1.0$ になると r.m.s. 值の最大値 は，物体壁面から離れた主渦の渦核近傍において存在して おり， $x / L=0.86$ において物体壁面から浮き上がってき た二次渦が主渦に吸収されたものと考えられる。また $\theta=$ $135^{\circ}$ 付近において r.m.s. 值の高い領域が存在し, 新しい 二次渦の発生が起きているものと考えられる. 第 5 図に $\alpha$ $=50^{\circ}, R e=1.8 \times 10^{4}$ における r.m.s. 分布を示す.この 図を見ると $\alpha=40^{\circ}$ の場合と異なり，各断面共に r.m. s. 值 は二次渦領域ではそれほど高くはなく主渦領域において高 い値を示しており, 特に主渦の渦核近傍で最大值を持つこ とが分かる，また物体後方に向かうにしたがい，渦核が物 体壁面から浮き上がり，r.m.s. 値の高い領域も拡大して いる様子が確認できる。

さらに $\alpha=40^{\circ}, R e=9.0 \times 10^{3}, x / L=0.21 \sim 1.0$ におけ る物体壁面近傍の r.m.s. 分布を第 6 図に示す.この図か ら $\theta=146^{\circ}$ 付近の二次渦領域内の r.m.s. 值が, 物体全体 にわたり極めて高い値を示していることが分かる.

4.2 確率泌度関数を用いた制離渦の分類 前述の r.m.s. 分布では，速度変動の周波数が低い場合において も, 変動の振幅が大きいと值が大きくなってしまう可能性 が考えられる，そこで本研究では確率密度関数を導入し，

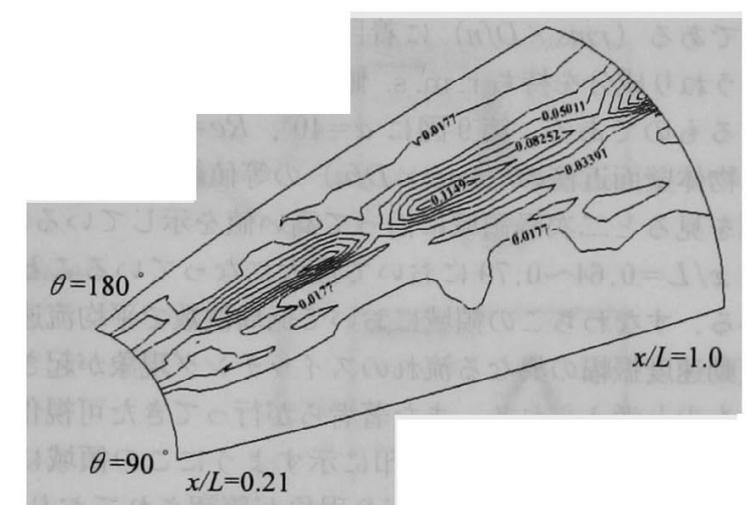

第6図物体壁面近傍における r.m.s. 分布 $\left(\alpha=40^{\circ}, R e=\right.$ $\left.9.0 \times 10^{3}\right)$

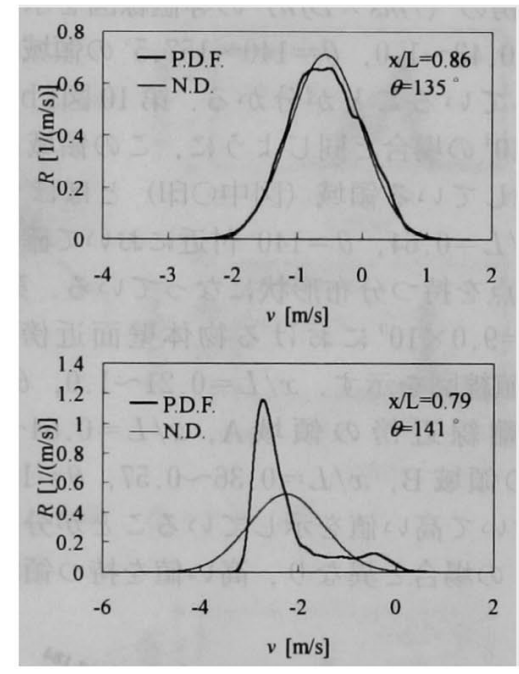

第 7 図 確率密度関数を用いた剝晟渦の分類

物体壁面近傍の剝離渦の流れの分類を試みた。すなわち各 測定点において 16,384のサンプリングデータから確率密 度関数 $R_{1}$ を算出し，この時得られる試料標準偏差 $\sigma$ から 正規分布 $R_{2}$ を求め, 次式の評価関数 $D f n$ を導入する.

$$
D f n=\int_{v_{1}}^{v_{2}}\left(R_{1}-R_{2}\right)^{2} \mathrm{~d} v
$$

$v_{1}, v_{2}$ は各測定点における速度デー夕の最小及び最大值で ある.第 7 図は $\alpha=40^{\circ}, R e=9.0 \times 10^{3}$ における確率密度 関数の分布形状を示している．隣接している湘定点である $x / L=0.86, \theta=135^{\circ}$ と $x / L=0.79, \theta=141^{\circ}$ の 2 点の分 布形状には明らかな相違がある.すなわち r.m.s. 值が同 レベルであっても $x / L=0.86, \theta=135^{\circ}$ の測定点のよう に, 速度変動の振幅が大きくさらに速度変動の周波数が高 い乱れの強い流れの場合には，確率密度関数は正規分布に 近づくものと考えられる。また $x / L=0.79, \theta=141^{\circ}$ の測 定点に見られる分布形状の場合には，周波数の低いうねり 成分が存在しているものと考えられる. 第 8 図に $x / L=$ $0.21 \sim 1.0$ に扔け $(1 / D f n)$ の等值線図を示す。この図 を見ると確率密度関数の分布形状は必ずしも r.m.s. 值の 大小と対応しておらず，正規分布に近い領域が点在してい ることが確認できる.そこで本研究では r.m.s. 值と $D f n$ 
の積である（ms×Dfn）に着目する。すなわち周波数の 低いうねり成分を持ち r. m.s. 值の高い領域を抽出しよう とするものである．第 9 図に $\alpha=40^{\circ}, R e=9.0 \times 10^{3}$ にお ける物体壁面近傍の ( $m s \times D f n)$ の等值線図を示す。こ の図を見ると二次渦領域に沿って高い值を示しているが, 特に $x / L=0.64 〜 0.79$ において最大になっていることが 分かる.すなわちこの領域において低周波数で平均流速及 び変動速度振幅の異なる流れのスイッチング現象が起きて いるものと考えられる．また著者らが行ってきた可視化実 験では，第 10 図(a)中のこ印に示すようにこの領域にお いて二次渦の渦核の折れ曲がり現象が確認されており ${ }^{14)}$, 第 9 図の分布はこの現象を定量的に裏付けるものであると 考えられる、第 11 図に $\alpha=40 ， R e=1.8 \times 10^{4} に お け る$

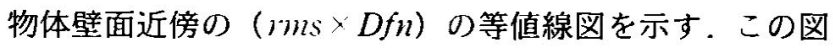
から $x / L=0.43 \sim 1.0, \theta=140 \sim 157.5^{\circ}$ の領域において高 い值を示していることが分かる.第 10 図(b)を見ると $R e=9.0 \times 10^{3}$ の場合と同じょうに，この領域は二次渦の 渦核が変動している領域 (図中○印) とほほ一致してい る. また $x / L=0.64, \theta=140^{\circ}$ 付近において確率密度関数 が 2 つの頂点を持つ分布形状になっている. 第 12 図に $\alpha$ $=50^{\circ}, R e=9.0 \times 10^{3}$ における物体壁面近傍の $(\mathrm{rms}$ 入 $D f n ）$ の等值線図を示す. $x / L=0.21 \sim 1.0, \theta=90 \sim 101^{\circ}$ の一次䣋離線近傍の領域 $\mathrm{A}, x / L=0.64 \sim 1.0, \theta=$ $101 \sim 129^{\circ}$ の領域 $\mathrm{B}, x / L=0.36 \sim 0.57, \theta=135 \sim 168^{\circ}$ の 領域 Cにおいて高い值を示していることが分かる.すな わち $\alpha=40^{\circ}$ の場合と異なり, 高い值を持つ領域が点在し

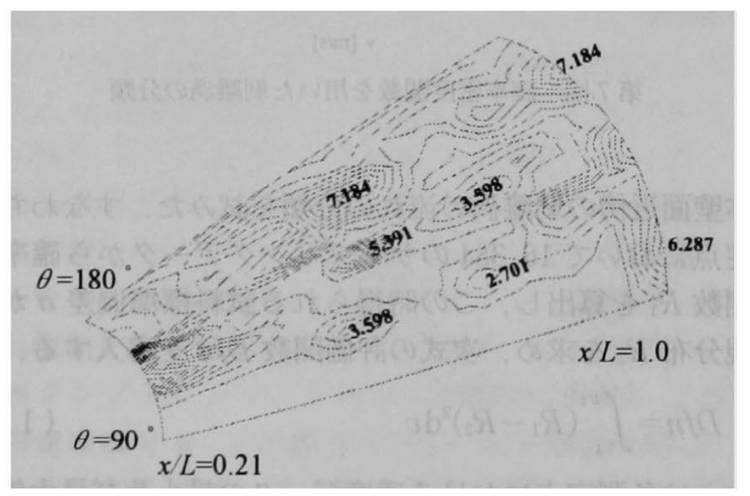

第 8 図 $(1 / D f n)$ 等值線図 $\left(\alpha=40, R e=9.0 \times 10^{3}\right)$
ており,三次元剝離渦発達のメカニスムについて久保田ら の提案したせん断層の不連続”の傾向を読み取ることがで き，剥離渦の非対称性を生み出す原因であると考えられ る.

第 13 図に $\alpha=40^{\circ}, R e=9.0 \times 10^{3}$ における各断面の $(m s \times D f n)$ の等値線図を示す. $x / L=0.64 \sim 0.79$ の一 次渦及び二次渦領域において值が高くなっていることが確 認できる．これらの領域の確率密度関数の分布形状は，い ずれの場合も正規分布から大きくずれており，低周波数の うねり成分を含んだ形となっている． $x / L=1.0$ において は值の高い領域が拡大し，等值線の中心位置は物体壁面か ら遠ざかっており，一次渦及び二次渦の浮き上がり現象が 起きているものと考えられる.第 14 図に $\alpha=40^{\circ}, R e=$ $1.8 \times 10^{4}$ における各断面の（ $\mathrm{rms} \times \mathrm{Dfn} ）$ の等值線図を示

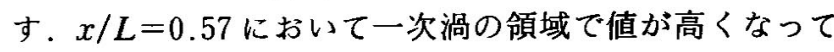
おり，物体後方に向かうにしたがって物体壁面から離れて いく様子が確認できる。また $\theta=90^{\circ}$ 付近の一次剝離線近 傍において值が高くなっていることが分かる． $x / L=0.86$

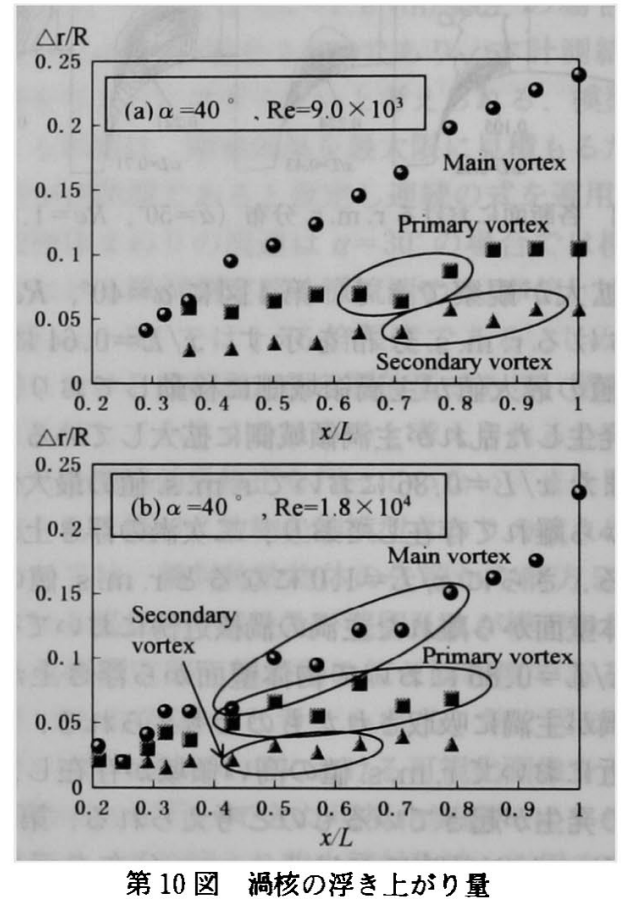

第 10 図 渦核の浮き上がり量

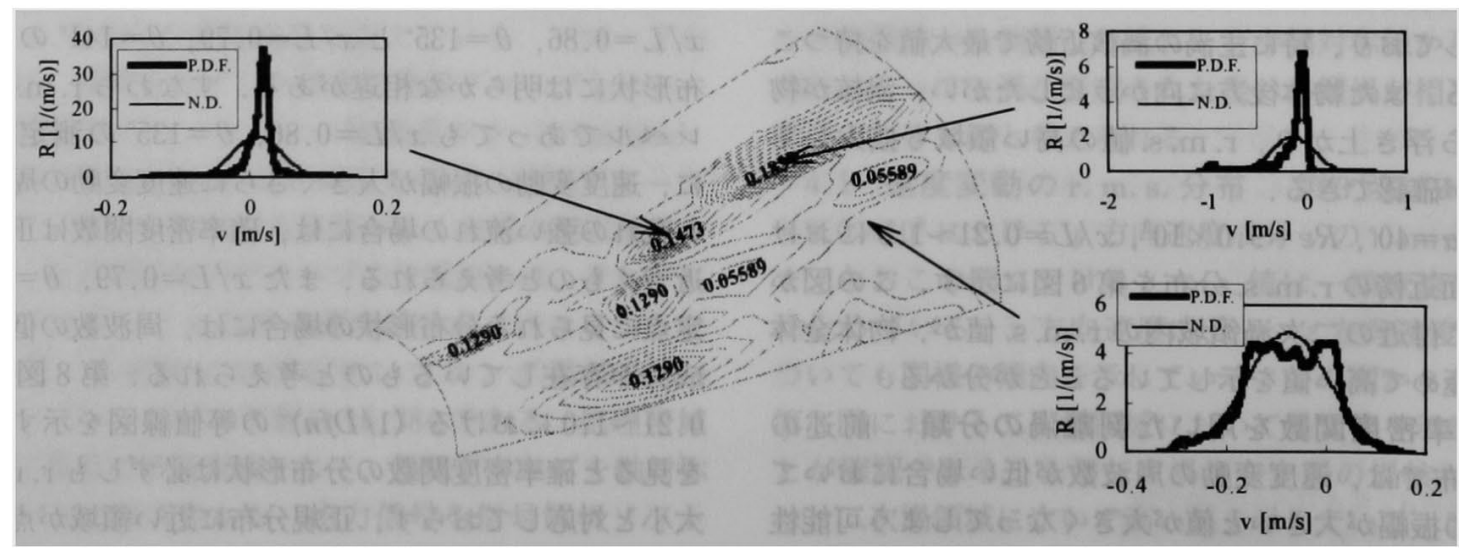

第 9 図 物体壁面近傍における $(r m s \times D f n)$ 等值線図 $\left(\alpha=40^{\circ}, R e=9.0 \times 10^{3}\right)$ 

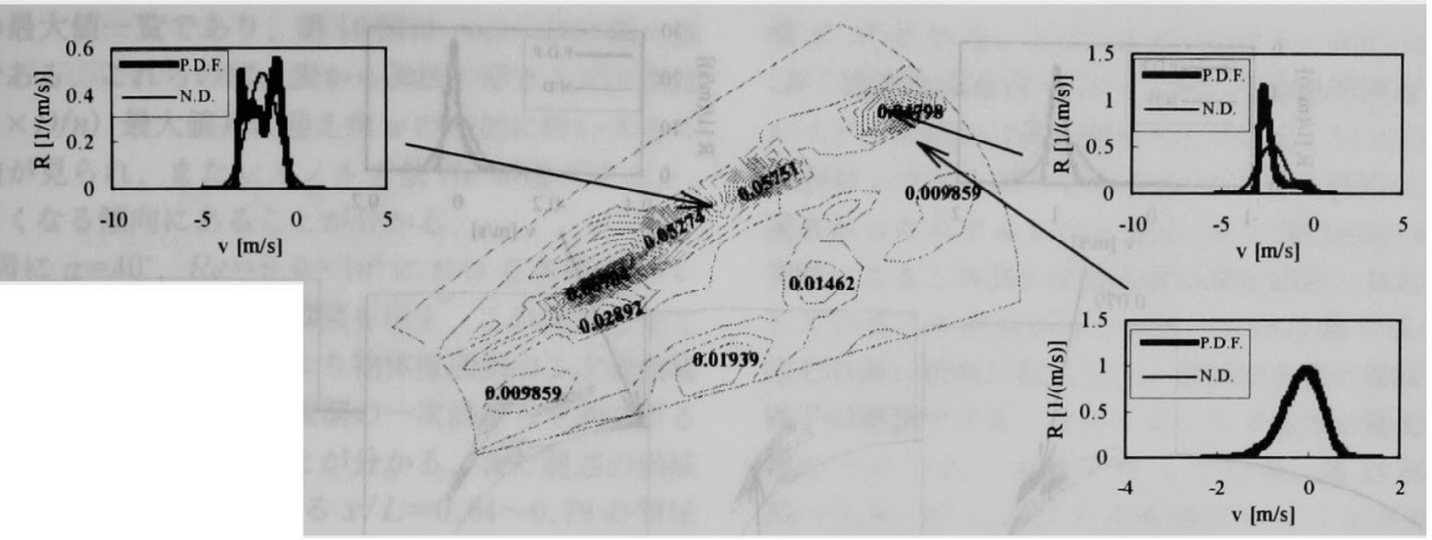

第 11 図物体壁面近傍における $(r m s \times D f n)$ 等值線図 $\left(\alpha=40^{\circ}, R e=1.8 \times 10^{4}\right)$

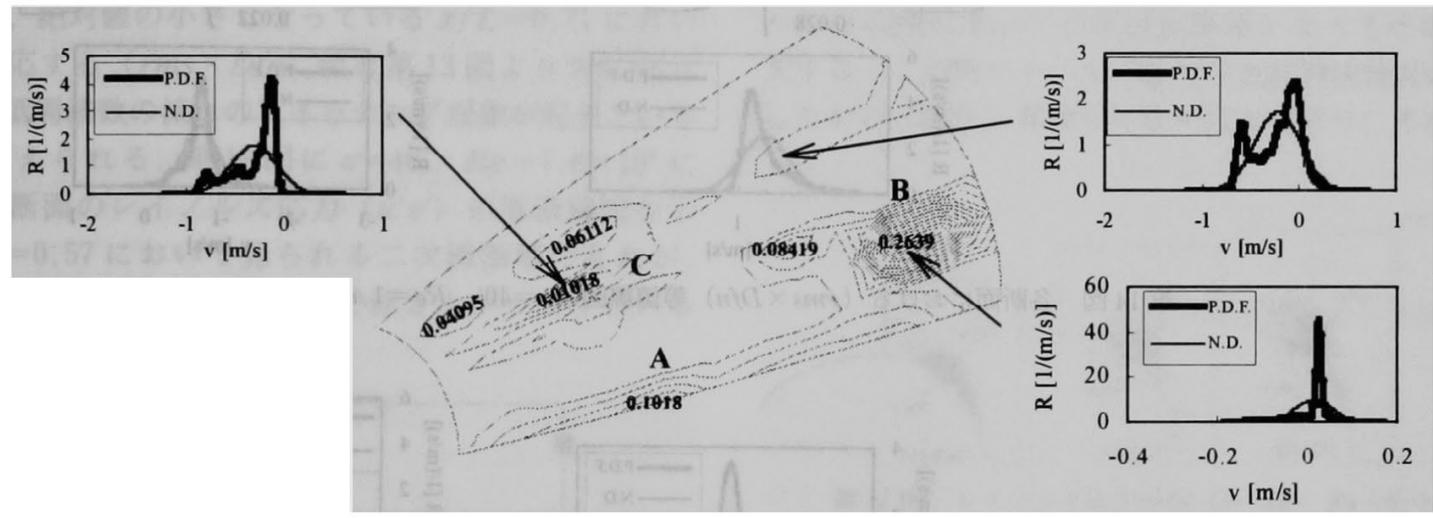

第 12 図 物体壁面近傍における $(m m \times D f n)$ 等值線図 $\left(\alpha=50^{\circ}, R e=9.0 \times 10^{3}\right)$

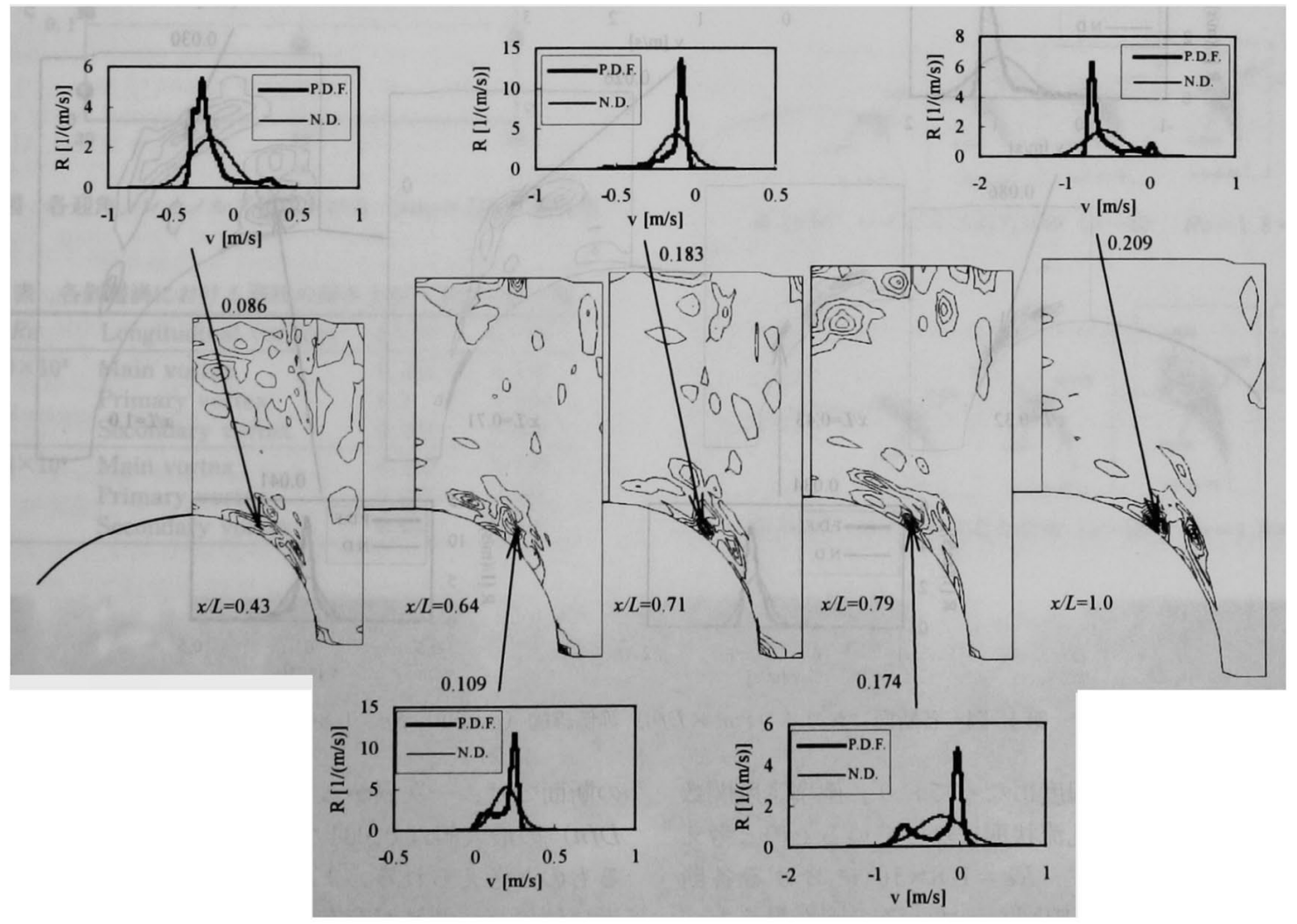

第 13 図 各断面における $(r m s \times D f n)$ 等值線図 $\left(\alpha=40^{\circ}, R e=9.0 \times 10^{3}\right)$ 


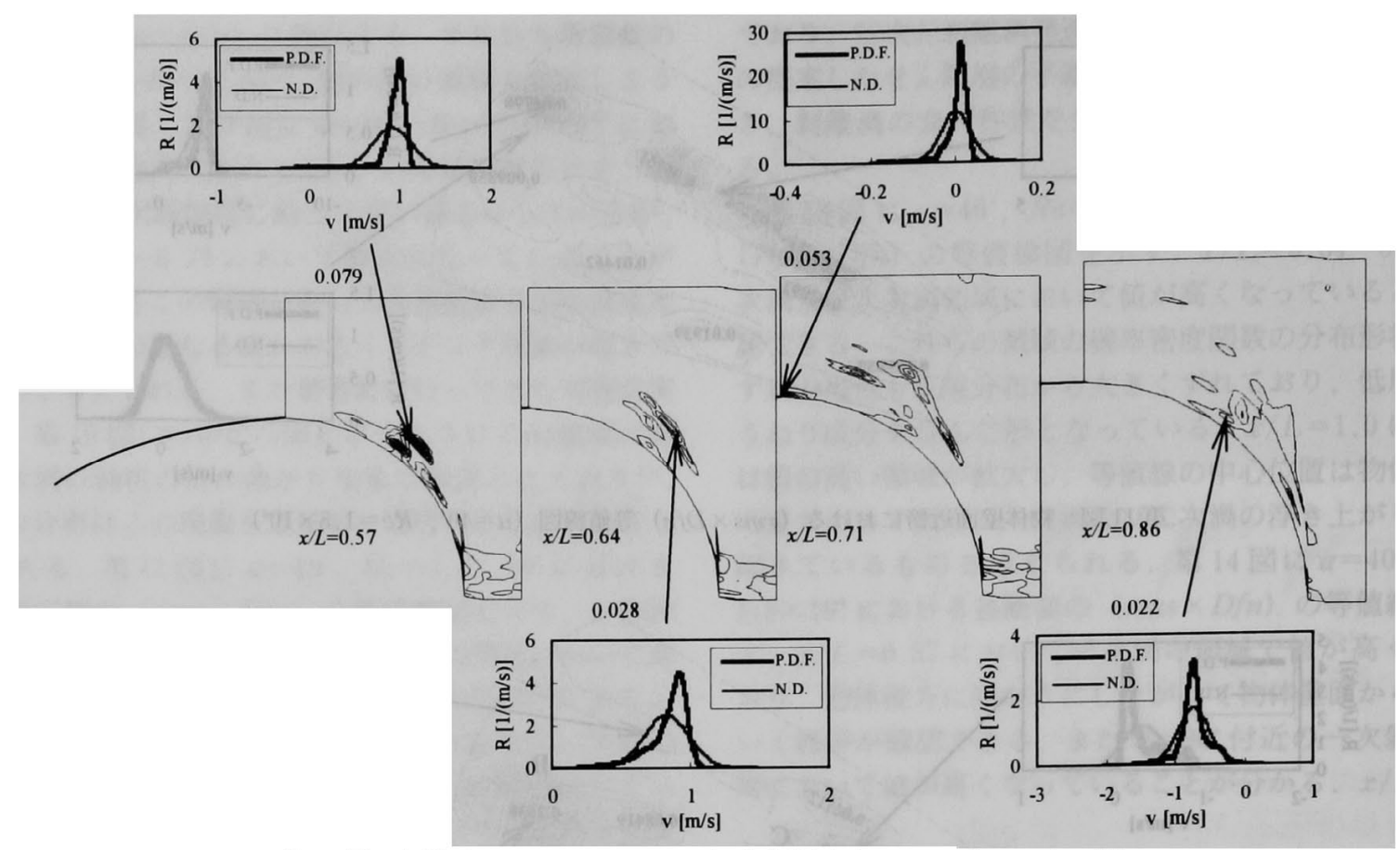

第 14 図 各断面における $(r m s \times D f n)$ 等值線図 $\left(\alpha=40^{\circ}, R e=1.8 \times 10^{4}\right)$

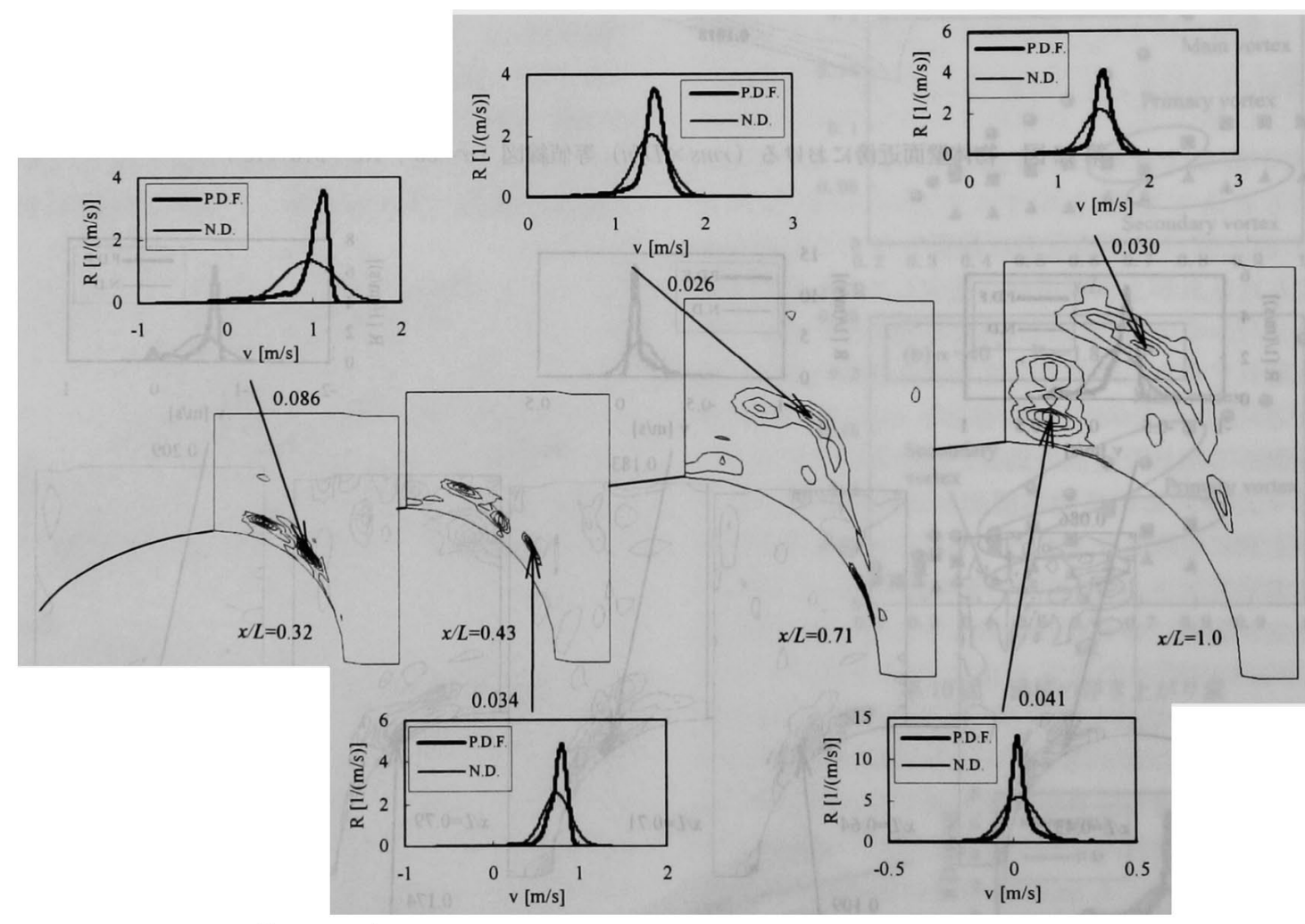

第 15 図各断面における $(r m s \times D f n)$ 等值線図 $\left(\alpha=50^{\circ}, R e=1.8 \times 10^{4}\right)$

になると最大值が 0.022 程度になっており，確率密度関数 は正規分布に近づきほほ乱流状態になっているものと考え られる.第 15 図に $\alpha=50^{\circ}, R e=1.8 \times 10^{4}$ における各断 面の $(r m s \times D f n)$ の等值線図を示す，この図を見ると一 次渦から主渦の渦核に至る領域において高い值を示し，物 体後方に向かうにしたがい一次渦が主渦に吸収され物体壁 面から浮き上がっていく様子が分かる． $x / L=0.43$ 以降 の断面では，一次渦から主渦の渦核に至る領域の（rms $\times$ Dfn）の最大值は 0.034 であり，ほほ乱流状態になってい るものと考えられる.また $x / L=1.0$ において $\theta=168^{\circ}$ 付 近に值の高い領域が存在し，主流領域からの吹き降ろしが 起きているものと考えられる，また，剩離渦特性の迎え角 $\alpha$, レイノルズ数 $R e$ との関係を第 1 表及び第 16 図に示 す.第 1 表は第 10 図で示された各剝離渦の渦核の浮き上 
がり量の最大值一覧であり，第 16 図は $r m s \times D f n$ 最大值 の傾向である．これらの図，表から渦核の浮き上がり量及 び ( $r m s \times D f n)$ 最大値共に迎え角 $\alpha$ の増加に伴い大きく なる傾向が見られ，またレイノルズ数 Re が増大すると， 值が小さくなる傾向にあることが分かる。

第 17 図に $\alpha=40^{\circ}, R e=9.0 \times 10^{3}$ における各断面のレ イノルズ応力 $\left(u^{\prime} v^{\prime}\right)$ の等值線図を示す．この図から全て の断面において，主渦の渦核より物体壁面側の二次渦領域 て負の值，主渦の渦核より主流側の一次渦から主渦に至る 領域において正の值を持つことが分かる。また前述の渦核 の折れ曲がり現象の観察される $x / L=0.64 \sim 0.79$ の領域 に着目すると、レイノルズ応力の最大及び最小值が変動し ていることが分かる.この傾向は二次渦領域において顕著

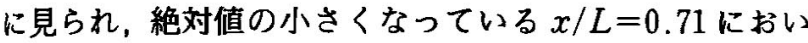
ては，対応する $(r m s \times D f n)$ 值は第 13 図より大になっ ており，低周波数の流れのスイッチング現象が起きている ものと考えられる.第 18 図に $\alpha=40^{\circ}, R e=1.8 \times 10^{4}$ に おける各断面のレイノルズ応力 $\left(u^{\prime} v^{\prime}\right)$ の等值線図を示 す. $x / L=0.57$ にいて見られる二次渦領域の乱れが， $x / L=0.64$ になると主渦領域まで浮き上がってきている

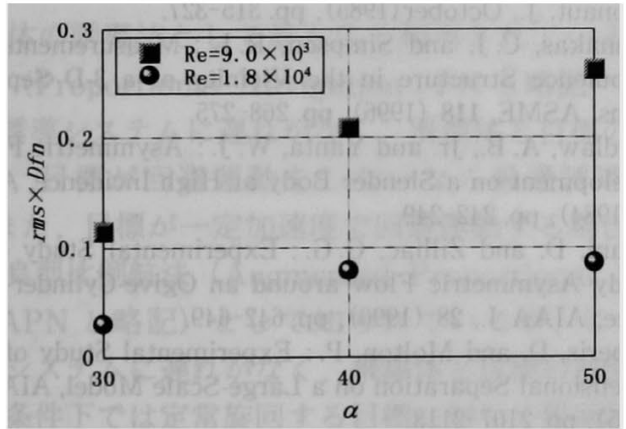

第 16 図 各迎角、レイノルズ数における $(r m s \times D f n)$ 最大値

第 1 表 各制離渦における渦核の浮き上がり量最大值一筧

\begin{tabular}{clll}
\hline$R e$ & Longitudinal vortices & $\alpha=30^{\circ}$ & $\alpha=40^{\circ}$ \\
\hline $9.0 \times 10^{3}$ & Main vortex & 0.155 & 0.238 \\
& Primary vortex & 0.1 & 0.104 \\
& Secondary vortex & 0.054 & 0.058 \\
\hline $1.8 \times 10^{4}$ & Main vortex & 0.139 & 0.229 \\
& Primary vortex & 0.083 & 0.081 \\
& Secondary vortex & 0.044 & 0.041 \\
\hline
\end{tabular}

様子が分かる. $x / L=0.71$ では $\theta=140^{\circ}, z / R=0.027$ $(R:$ 模型後端直径 $=37.5 \mathrm{~mm})$ の物体壁面近傍において レイノルズ応力は高い値を示している．以上のことから二 次渦が $x / L=0.57 \sim 0.71$ にかけて物体壁面に近づいたり 遠ざかったりするものと考えられ，第 10 図(b)の可視化 実験による二次渦の渦核位置の測定結果と良好な一致を示 していることが分かる， $x / L=0.86$ 以降ではレイノルズ 応力の高い領域が拡大し，一次渦が主渦に吸収されている 様子が確䜑できる，またレイノルズ応力の最大値も後方に 向かうにつれて大きくなっている。第 19 図に $\alpha=50^{\circ}$, $R e=1.8 \times 10^{4}$ における各断面のレイノルズ応力 $\left(u^{\prime} v^{\prime}\right)$ の等値線図を示す．この図を見ると第 5 図の r.m.s. 分布 と良好な一致を示していることが分かる.すなわち $x / L$ $=0.43$ 以降においては乱流䟝離渦となってその領域が拡 大する．この時レイノルズ応力分布は物体後方に向かうに したがい, 非常に複雑な形状を呈しており，その結果一次

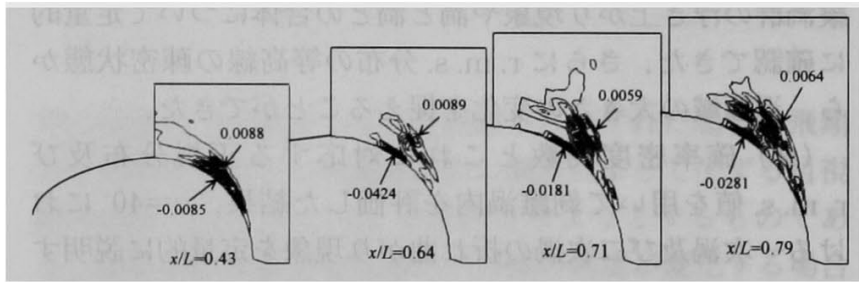

第 17 図 レイノルス応力分布 $\left(\alpha=40^{\circ} ， R e=9.0 \times 10^{3}\right)$

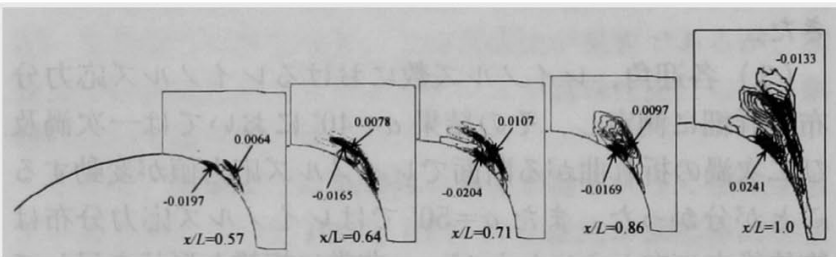

第 18 図 レイノルス応力分布 $\left(\alpha=40^{\circ} ， R e=1.8 \times 10^{4}\right)$

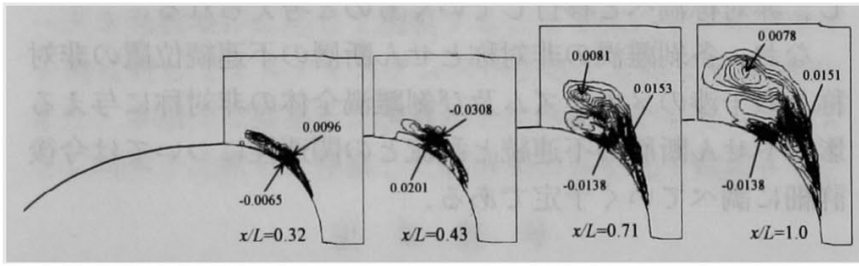

第 19 図 レイノルス応力分布 $\left(\alpha=50^{\circ}, R e=1.8 \times 10^{4}\right)$

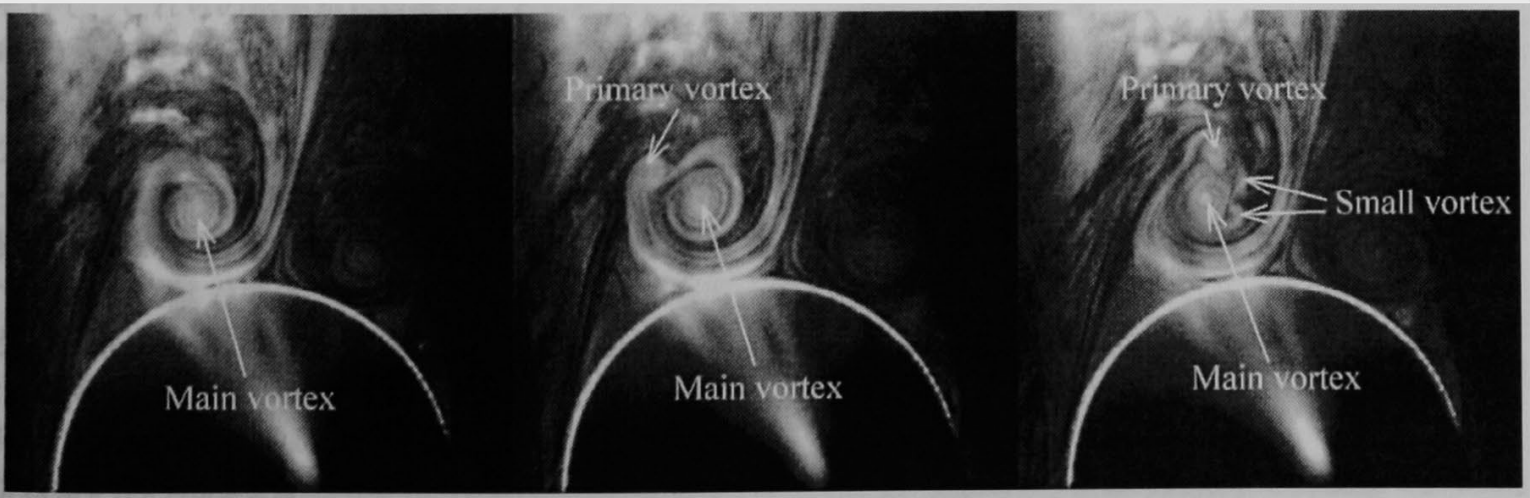

第 20 図 可視化画像 $\left(\alpha=50^{\circ}, R e=9.0 \times 10^{3}, x / L=1.0\right)$ 
渦が主渦に吸収され主渦の渦核が振動し, 非対称渦へと移 行していくものと考えられる. 第 20 図に $\alpha=50^{\circ}, R e=$ $9.0 \times 10^{3}, x / L=1.0$ におけるレーザライトシート光とフ オグジェネレータを用いた剥離渦の可視化画像を示す。こ の図を見ると一次渦が主渦に吸収されて，その結果主渦の 渦核近傍に小さな渦が発生している様子が確認できる。 $x / L=0.43$ においてはこのような可視化画像は得られな かったが、同様なメカニズムが生起してr.m.s. 值及びレ イノルズ応力值を大きくしているものと考えられる。

\section{5. 結論}

迎角を持つ軸対称放物体背後に生じる剥離洞について， 定温度型熱線流速計を用いて変動速度場を詳細に測定し， 以下の結論を得た。

（1）各迎角、レイノルズ数におけるr.m.s. 分布を詳 細に導出し，その結果迎角によって r.m.s. 值が最大とな る渦領域は異なることが確認できた。また各迎角における 縦渦群の浮き上がり現象や渦と瀜との合体について定量的 に確認できた。さらにr.m.s.分布の等高線の柾密状態か ら，渦領域の大きさの変化を捉えることができた．

（2）確率密度関数とこれに対応する正規分布及び r.m.s. 值を用いて剥離渦内を評価した結果， $\alpha=40^{\circ}$ にお ける一次渦及び二次渦の折れ曲がり現象を定量的に説明す ることが可能となった。また $\alpha=50^{\circ}$ においては乱流剥離 渦領域が模型前方まで拡大している様子を捉えることがで きた。

（3）各迎角, レイノルズ数におけるレイノルズ応力分

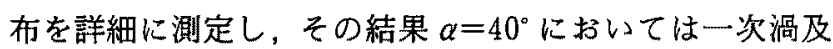
び二次渦の折れ曲がる断面でレイノルズ応力值が変動する ことが分かった．また $\alpha=50^{\circ}$ ではレイノルズ応力分布は 物体後方に向かうにしたがい，非常に複雑な形状を呈して おうりその結果，一次渦が主渦に吸収され主渦の渦核が振動 し, 非対称渦へと移行していくものと考えられる。

なお，各刎離渦の非対称とせん断層の不連続位置の非対 称との干涉のメカニズム及び䟝離渦全体の非対称に与える 影響やせん断層の不連続と乱流との関連性については今後 詳細に調べていく予定である。

本研究を行うにあたって, 千葉大学学部生の菊地三朗
君, 高楯直人君, 木更津高専 5 年生の江副敬史君, 松永浩 嗣君の協力を得ました。ここに記して感謝の意を表しま す.

\section{参 考 文 献}

1) Jia, M., Watanuki, T. and Kubota, H.: The Visualization of Separated Flow over Slender Bodies at High Angles of Attack, J. Visualization Soc. Jpn., 14 (1994), pp. 243-252.

2) Przirembel, C. E. G. and Shereda, D. E. : Aerodynamics of Slender Bodies at High Angles of Attack, J. Spacecraft, 16 (1979), pp. 10-14.

3) Ericsson, L. E. and Reding, J. P. : Dynamics of Forebody Flow Separation and Associated Vortices, J. Aircraft, 22 (1985), pp. 329-335.

4) Wang, K. C., Zhou, H.C. and Hu, C. H.: Three-Dimensional Separated Flow Structure over Prolate Spheroids, Proc. $R$. Soc. Lond. A, 421 (1990), pp. 73-90.

5) Meier, H. U. and Kreplin, H. P.: Experimental Investigation of the Boundary Layer Transition and Separation on a Body of Revolution, Z. Flugwiss. Weltraumforsch., 4 (1980), pp. $65-71$.

6) Kreplin, H. P. and Stager, R. : Measurements of the ReynoldsStress Tensor in the Three-Dimensional Boundary Layer of an Inclined Body of Revolution, Proc. 9th Symp. "Turbulent Shear Flows," Kyoto, Japan, 1993, pp. 2.4.1-2.4.6.

7) Poll, D. I. A : On the Effects of Boundary-Layer Transition on a Cylindrical Afterbody at Incidence in Low-Speed Flow, Aeronaut. J., October (1985), pp. 315-327.

8) Chesnakas, C. J. and Simpson, R. L.: Measurements of the Turbulence Structure in the Vicinity of a 3-D Separation, Trans. ASME, 118 (1996), pp. 268-275.

9) Wardlaw, A. B., Jr. and Yanta, W. J. : Asymmetric Flowfield Development on a Slender Body at High Incidence, AIAA J., 22 (1984), pp. 242-249.

10) Degani, D. and Zilliac, G. G. : Experimental Study of Nonsteady Asymmetric Flow around an Ogive-Cylinder at Incidence, AIAA J., 28 (1990), pp. 642-649.

11) Barberis, D. and Molton, P.: Experimental Study of ThreeDimensional Separation on a Large-Scale Model, AIAA J., 33 (1995), pp. 2107-2113.

12) Ishide, T. and Nishikawa, N. : Experimental Study of Unsteady Flow Behavior in Separated Flow along Blunt Body, Proc. 31st Aircraft Symp., 1993, pp. 140-143.

13) Nishikawa, N. and Ishide, T.: Visualization and Measurement of Separated Flow over Axisymmetric Paraboloid, Proc. 2nd Asian-Pacific Conf. Aerospace Technology and Science, Dun Huang, 1997, pp. 137-142.

14) Ishide, T., Nishikawa, N. and Mikami, F.: Smoke Visualization and Hot Wire Measurements of Three Dimensional Separated Flows, J. Jpn. Soc. Aeronaut. Space Sci., 48 (2000), pp. 27-33. 